\title{
Demographic \& Clinical Correlates of Admission into a Specialized Psychiatric Inpatient Service for Children and Adolescents in Egypt: An Observational Retrospective Study
}

Mohammad Seleem ( $\sim$ seleemm@med.tanta.edu.eg )

Tanta University Faculty of Medicine https://orcid.org/0000-0001-9926-0686

\section{Reham A. Amer}

Tanta University Faculty of Medicine

\section{Research}

Keywords: Child, Adolescent, Inpatient, Psychiatry, Egypt

Posted Date: August 11th, 2020

DOI: https://doi.org/10.21203/rs.3.rs-55270/v1

License: @ (i) This work is licensed under a Creative Commons Attribution 4.0 International License. Read Full License

Version of Record: A version of this preprint was published at Journal of Psychiatric and Mental Health Nursing on January 31st, 2021. See the published version at https://doi.org/10.1111/jpm.12730. 


\section{Abstract}

Background: To our knowledge, this is the first study that aims to investigate the demographic and clinical correlates of admission into a specialized inpatient psychiatric unit for children and adolescents in Egypt and the Arab world.

Methods: The files of all new cases who presented for care in the outpatient service for children and adolescents in Tanta University between July 2017 and December 2019 were reviewed. Of the 1195 files reviewed, 100 patients were admitted to the inpatient unit for 133 admission episodes with an average duration of 18.5 days per episode.

Results: The most common diagnosis among admitted youth was disruptive behavior disorder but having a diagnosis of bipolar disorder, eating disorder, or trauma related disorders predicted admission more powerfully than did the diagnosis of disruptive behavior disorder. Physical and sexual abuse were both associated with higher rates of admission, readmission and longer duration of admission.

Conclusions: Except for having more percentage of youth with disruptive behavior disorders, and less percentage of those with eating disorders, the characteristics of youth in need for admission into psychiatric inpatient unit is comparable to those reported in other parts of the world.

\section{Background}

At any given point of time, it is estimated that one in every 4-5 people under the age of 18 suffers from a psychiatric disorder (Costello, Mustillo, Erkanli, Keeler, \& Angold, 2003; Jaffee, Harrington, Cohen, \& Moffitt, 2005). Although most children and adolescents with behavioral problems can be managed at their natural environment, a significant minority of this population need to be admitted to inpatient facilities (Blader, 2004, 2011; Case, Olfson, Marcus, \& Siegel, 2007; Glick, Sharfstein, \& Schwartz, 2011). Residential facilities for children and adolescents, mainly applying discipline to delinquent youth and general care for mentally retarded orphans, have existed in the US since the nineteenth century (Jemerin \& Philips, 1988). More therapeutically oriented facilities have not been established till 1930s and 1940s (Association, 1957; Harper, 1987; Jemerin \& Philips, 1988; Lewis, 1985). In other parts of the world, Child and adolescent inpatient services have developed from the theoretical concept of "therapeutic milieu" that aims to shape the behavior of youth at early stage of personality development (Kennard, 1983).

In the second half of the twentieth century, the availability of child psychiatric inpatient services increased rapidly in the US and Europe, with several changes in trends of admission, quality of care and targeted population (Worrall-Davies, 2015). An increasing number of admissions, shorter length of stay, with multiple changes in diagnostic patterns of youth in need for admission was reported in several studies. For example, a comprehensive study of overall psychiatric admissions in the US between 1996 and 2007 showed much more increase (180\%) in children, and adolescents (141\%), as compared to adults (108\%) (Blader, 2011). In 2014, approximately 606,000 adolescents received inpatient or residential specialty mental health services in the US (Rachel N. Lipari, 2016). The number of psychiatric inpatient beds dedicated to adolescents in England and Wales increased from 900 beds in 1999 to 1128 beds by 2006, with increase in adolescent only unit and general units (i.e. units which admit both children and adolescents) but $30 \%$ decrease in units dedicated only to children under 14 years of age (O'Herlihy et al., 2018). Inpatient admission rates for children and adolescents also increased by $38.1 \%$ in Germany between 2000 and 2007 with a sharp increase of cases for depressive disorders (219.6\%) and hyperkinetic disorders (111.3\%) (Holtmann et al., 2010). A recent study from Spain also reported an increase of youth under 18 years old admitted to psychiatric units from 27,7 per 100000 inhabitant in 2005 to 49.8 per 100000 inhabitant in 2015 (Llanes-Alvarez et al., 2019). In a study carried out in a French public hospital, $2.0 \%$ of the children and adolescents cared for in the emergency department were admitted to the psychiatric emergency department (Boyer et al., 2013).

A retrospective meta-analysis of 34 studies (Pfeiffer \& Strzelecki, 1990), in addition to a prospective one-year follow up study (Green et al., 2007) all highlighted meaningful clinical improvement with child and adolescent psychiatric inpatient treatment across all diagnostic categories. Two long-term follow up studies (Fuchs et al., 2016; Healy \& Fitzgerald, 2000) reported that most of children and adolescents admitted to inpatient psychiatric units still met the criteria of psychiatric disorders during their adulthood but only $26 \%$ of these patient were readmitted to psychiatric inpatient units as adults. Despite the widespread use of 
inpatient services for children and adolescents with mental health problems in developed countries, the costs and benefits of such practice and the call for alternative approaches to deal with their problems in less restrictive settings have been the focus of a long, ongoing debate among experts (Boge, Schepker, \& Fegert, 2019; Branik, 2001; Edwards et al., 2015; Glick et al., 2011; Mattejat, Hirt, Wilken, Schmidt, \& Remschmidt, 2001). In a randomized controlled study in two German centers for child and adolescent mental health, authors concluded that residential treatment can be replaced by home treatment with no significant differences in therapeutic outcome in at least $15 \%$ of those patients treated in inpatient setting (Mattejat et al., 2001). In 2008, a systematic review (Shepperd et al., 2009) identified eight worldwide commonly used alternative models to inpatient care for youth with complex mental health needs, such as multisystemic therapy, day hospitals, intensive specialist outpatient service. However, a more recent review reported high levels of parental burden and complex emotional reactions associated with engagement with such alternative interventions (Vusio, Thompson, Birchwood, \& Clarke, 2019).

A review of potential risks that affects children and adolescents using inpatient child and adolescent mental health services in the UK concluded that dislocation from normal life, together with stigmatization, are the main potential risks caused by hospitalization of youth with severe psychiatric problems. However, the same review reported little evidence supports the existence of better options to care for this population other than inpatient setting (Edwards et al., 2015). In another study, a sample of adolescents interviewed within 7 days of discharge from their first psychiatric hospitalization, the participants reported "a little" stigma towards their admission (Moses, 2011). Having an assisted transition from an inpatient psychiatric service to school and open community was found to facilitate the re-integration of discharged youth into their natural environment and decreased rates of re-admission (Weiss et al., 2015)

Few studies explored the characteristics of children and adolescents admitted to psychiatric inpatient units outside the US and Europe (Bharath, Srinath, Seshadri, \& Girimji, 1997; Jacob, Seshadri, Girimaji, Srinath, \& Sagar, 2013). An early study from India (Bharath et al., 1997), the most common diagnoses among admitted children were hysterical neurosis (30.8\%), psychoses (25.2\%), conduct disorder (10.5\%) and hyperkinetic syndrome (9.8\%) with average duration of stay was 4-12 weeks. Egypt population was recently estimated to exceed 100 million people, with approximately $43 \%$ of this number aged less than 19 years ((CAPMAS), 2018). However, there is absence of studies reporting the case of admission of children and adolescents into specialized psychiatric inpatient services in Egypt and the Arab region. The first specialized university-affiliated psychiatric inpatient unit for both children and adolescents was started in Tanta psychiatry and neurology center in 2013 to serve a wide catchment area of about 13 million people. The unit included 10 beds for both children and adolescents while 7 more beds were later added in 2017 to serve adolescents only. In a previous report (Seleem, Amer, Romeh, \& Hamoda, 2019), our team described the demographic and clinical characteristics of children seeking psychiatric advice in our outpatient service. The current study aims to identify the demographic and clinical correlates of admission into our psychiatric inpatient unit for children and adolescents.

\section{Methods}

This descriptive study was carried out through reviewing the files of children and adolescents who were admitted to the inpatient psychiatric unit and comparing them to those who received outpatient service only in Tanta Psychiatry and Neurology Center during a period of 30 months between July 2017 and December 2019. The files included the data collected by trained social workers about the demographic and socio-economic status of the families coming for psychiatric advice in addition to medical and developmental history obtained by child psychiatry fellows. As corporal punishment is relatively common in Arab culture (Dwairy \& Menshar, 2006; El.Makzoum, 2015), physical abuse was technically defined as any physical punishment that left a mark on the skin of the child for a period of more than 24 hours. Touching the child in a sexual manner or showing him any kind of media with explicitly sexual or pornographic content was considered as sexual abuse as defined by Egyptian law (Parliament), 2008 (amendment) - Original Act 1996).

An Arabic translated and validated psychiatric interview, namely the MINI International Neuropsychiatric Interview for Children and Adolescents, (Ghanem, 1998; Ibrahim M, 2002; Sheehan D, 1997) was used to confirm psychiatric diagnoses. Both parents and children were interviewed except for the case of preschoolers where only parent were interviewed. Trained bachelor's degree interviewers did the interviews and the results were all reviewed and confirmed by a trained child and adolescent psychiatrist (the 
first author). The questions of the MINI-kid were sometimes modified to reflect the diagnostic criteria of the DSM-5 (Association, 2013). When needed, the intellectual abilities of children and adolescents were evaluated using the Arabic translation of the Stanford-Binet Intelligence quotient (I.Q) fourth edition (Melika, 1998; Thorndike, 1986), The decision to admit a case was made by the consultant attending child psychiatrist (the first author) at time of evaluation according to predetermined admission criteria. These criteria were adapted with little modifications from the criteria determined by the American Academy of Child and Adolescent psychiatry (AACAP) (Psychiatry, 1989). The adapted criteria include showing a behavior that poses an actual or imminent danger to him or herself or to others, requiring a period of intensive observation by skilled professionals to make a diagnosis, being in need for unusually high doses of medication that requires close monitoring, and failure to improve in other, less restrictive settings. The decision to discharge a case was based on consensus of a treatment team that includes residents, nurses, psychologists, and social workers working with the case and agreeing that the admission criteria no longer apply to the patient.

Data was analyzed using IBM SPSS software package version 20.0. (Armonk, NY: IBM Corp) (Corp., Released 2011). Simple descriptive analysis was utilized to describe the demographic and clinical characteristics of the sample. Logistic regression was used to explore the role of different variables in predicting admission while univariate Linear regression was used to explore the role of the same variables in predicting number of admissions and the total duration of admission (only the significant results was shown in the table). Significance of the obtained results was judged at the $5 \%$ level.

\section{Results}

The medical records of 1278 patients presenting to the unit during the designated period of the study were reviewed. Eighty files were excluded due to missing data while 3 more files were found to be for adult cases (age > 18 years old). Of our final sample (n $=1195)$, only 100 cases were admitted to the inpatient unit ( $8.4 \%$ of the total sample) for 133 admission episodes. Most of our sample (73\%) were admitted once, $23 \%$ were admitted twice, $3 \%$ for 3 times and only one case (1\%) was admitted 5 times. The duration of the last admission ranged from 3 to 60 days with an average of $18.5 \pm 10.9$ days. Regarding the DSM-5 diagnostic categories, the diagnoses received by $59 \%$ of the sample were included in one DSM- 5 diagnostic category, $31 \%$ of the sample received diagnoses from two categories, $8 \%$ from 3 categories, and $2 \%$ from 4 categories. (data not shown).

The children admitted to the inpatient unit were significantly older than those who received outpatient services $(p \leq 0.001)$. The age of the inpatient group ranged from 3 to 18 years with a mean age of $11.6( \pm 3.7)$ while that of the outpatient group ranged from 18 months to 18 years, with a mean age of $7.4( \pm 3.8)$ years (table 1$)$. Significantly more adolescents (54\%) and less preschoolers (5\%) were admitted to the inpatient unit as compared to the percentage of the same age categories in the outpatient group ( $16.1 \%$ and $36.3 \%$ respectively). Only $25 \%$ of the inpatient and $32.1 \%$ of the outpatient groups were females with no significant difference between the two groups. Admitted youth were more likely to come from urban residence $(60 \%$ vs. $40.6 \%)$ and less likely to be living with both parents ( $80 \%$ vs. $89 \%$ ) as compared to youth who needed only outpatient services. The admitted youth were also more likely to have fathers who did not finish high school (37\% vs. $25.3 \%$ ), but a similar difference was not significant in mothers. No significant differences were found between both groups regarding family income and child enrollment in school ( $p$-values >0.05) (table 1).

History of birth complications, delayed milestones, medical illness, and to less extent a family history of psychiatric illness were all significantly less common in admitted youth as compared to outpatient group. Physical punishment was reported in about one fifth of cases with no significant differences between inpatient and outpatient groups. However, both physical and sexual abuse were reported in the inpatient group more frequently than in the outpatient group, with more significant difference between both groups regarding sexual abuse (8\% vs. 1.4\%). On the other hand, IQ, birth order or the presence of comorbidity (more than one diagnosis) did not show any significant differences between both groups ( $\mathrm{p}$-values $>0.05$ ) (table 2 ). The most frequently diagnostic categories received by admitted children included disruptive disorders (42\%), followed by borderline intellectual abilities (BIF) (30\%), ADHD (22\%), and depressive disorders (18\%). Admitted youth were more likely to receive a diagnosis of disruptive disorders, bipolar disorders, psychotic disorders, eating disorders or trauma related disorders but less likely to receive a diagnosis of autism spectrum disorder, communication disorders, elimination disorders or neurological disorders (table 3). 
Older age was one of the significant predictors for both admission and longer duration of admission $(\mathrm{OR}=1.3, \mathrm{~B}=0.7)$. The school age category had more than 6-fold likelihood to be admitted as compared to the preschool age category while being an adolescent raised, in turn, the likelihood to be admitted almost four times as compared to be a school aged child $(\mathrm{OR}=6.2)$. Coming from urban background, having a deceased parent or an illiterate father also predicted admission in our unit $(\mathrm{OR}=2.2$, $3.6,1.9$ respectively). Being out of school was associated with spending more time in the inpatient service $(B=7.4)$ while having a history of birth complications, delayed milestones, or medical illness decreased the likelihood of being admitted $(\mathrm{OR}=0.2,0.4$, and 0.2 , respectively). Being a subject of sexual abuse specifically increased the likelihood of being admitted $(\mathrm{OR}=6.3)$, but all types of abuse were associated with more readmissions, and longer duration of admission $(B=0.2,2.3$ respectively)

The most powerful predictor of admission among diagnostic categories was bipolar disorders $(\mathrm{OR}=14.4)$, followed by eating disorders $(O R=11.2)$, trauma related disorders $(O R=6.7)$, disruptive disorders $(O R=5.6)$, and finally psychotic disorders $(O R=$ 3.8). Both psychotic $(B=0.7)$ and disruptive disorders $(B=0.3)$ predicted more frequent admissions while both sexual and neurological disorders predicted longer duration of admission ( $O R=26.7$ for both). On the other hand, communication disorders $(\mathrm{OR}=0.08)$, neurological disorders $(\mathrm{OR}=0.1)$, autism spectrum disorder $(\mathrm{OR}=0.2)$, and elimination disorders $(\mathrm{OR}=0.4)$ all predicted that the child would receive outpatient service only (table 4; Figs. 1-4)

\section{Discussion}

To our knowledge, this is first study to describe the demographic and clinical correlates of admission into a specialized inpatient unit for child and adolescent psychiatry in Egypt and other Arabic-speaking countries. Given that our unit is the only specialized inpatient unit in our catchment area which have a population of about 13 million people, $43 \%$ of which are under the age of 19 years ((CAPMAS), 2016), the estimated number of admission episodes per year will be 0.8 per 100000 inhabitants under 19 years old. This number is well below numbers of admissions reported for admission of all patients under 18 years old in other countries such as Spain (49.8 per 100000) (Llanes-Alvarez et al., 2019) and Germany (705 per 100000) (Holtmann et al., 2010). Studies from UK (James, Clacey, Seagroatt, \& Goldacre, 2010) report the admission of 20 children under 10 years old and 220 adolescents per 100000 youth inhabitants, compared to 283.04 and 969.03 for the same age categories in the US (Blader, 2011). This difference could be explained by the relatively recent start of the practice in Egypt and scarce beds available for this population. It might also be explained by the possibility of admission of youth, especially older adolescents, in adult psychiatric wards.

We report a relatively short length of stay per admission with a mean of 18.5 days. This duration is similar to that reported in Spain (Llanes-Alvarez et al., 2019), shorter than that reported in Germany (22.2 days) (Holtmann et al., 2010) and in New Zealand (27.3 days) (Swadi \& Bobier, 2005), but longer than that reported in the US (7.4 days) (Bardach et al., 2014; Case et al., 2007). The median length of stay of a child in a psychiatric inpatient unit in the US has reportedly declined from 12.2 days to 4.5 days between 1990 and 2000 (Case et al., 2007). Given that the major portion of the improvement was suggested to occur during the first 3 weeks of admission (Swadi \& Bobier, 2005), the "ultrashort" period of hospitalization which became a trend in the US in the last decade (Case et al., 2007) was criticized as it might interfere with the long-term recovery process and increase rates of short term readmission in the so called "revolving door phenomenon" (Glick et al., 2011; Simila, Hakko, Riipinen, \& Riala, 2018). Better outcomes were independently predicted by longer length of stay in the inpatient setting (Green et al., 2007). Our reported percentage of readmission (27\%) within the period of follow up (30 months) was lower the that reported in a previous study in the US in which $43 \%$ of youth were readmitted during a similar period of follow up (30 months) (S. James et al., 2010). In another study, the reported rates of readmission of discharged youth within one year was estimated to be as high as $34 \%$, with $81 \%$ of readmissions occurring in the 90 days next to discharge (Blader, 2004). A recent meta-analysis of 33 studies (Edgcomb, Sorter, Lorberg, \& Zima, 2020) reported a readmission rate of $13.2 \%$ during an average follow up period of 13.1 months, a comparable rate of our reported finding.

The mean age of our inpatient sample is similar to that reported by Grupp-Phelan and colleagues (Grupp-Phelan et al., 2009) but less than that reported by Boyer and Llanes-Álvarez and their colleagues (Boyer et al., 2013; Llanes-Alvarez et al., 2019). The rare occasion of admitting young children less than 5 years of age could not be considered an unprecedented practice in the current study as for every 100000 children under the age of 5 years, 10 children were reportedly admitted to inpatient psychiatric units in 
the US (Case et al., 2007). The greater need for admission among adolescents coming from urban areas in our sample replicates previous studies reporting similar results in different cultures (Case et al., 2007; Grupp-Phelan et al., 2009; Llanes-Alvarez et al., 2019) and might, together with higher parent education, reflect more family awareness and easier access to service but might also reflect more behavioral problems with urbanization. However, the percentage of male patients (75\%) in our sample was higher than expected from the actual percentage of male children in our population (51.2\%) and from previous studies in other parts of the world (Boyer et al., 2013; Case et al., 2007; Llanes-Alvarez et al., 2019). This high percentage might reflect the cultural tendency to give attention to behavioral problems more in males rather than in females. Although the percentage of children living with both parents is less in our admitted than in outpatient group, this percentage among admitted youth is still less than reported in other cultures (Mendonca, Pantano, Casella, \& Scivoletto, 2017), a finding that might reflect the conservative nature of Egyptian but might also reflect the need to reach out to more troubled families and residential homes in our community. Unsurprisingly, we report a clear association between physical and sexual abuse of children and admission, readmission, and longer duration of admission among our inpatient sample of youth, a fining previously reported in several studies (Bobier \& Warwick, 2005; Mendonca et al., 2017).

The distribution of our sample of admitted youth among diagnostic categories were more or less similar to previously reported results (Case et al., 2007; Edelsohn, Braitman, Rabinovich, Sheves, \& Melendez, 2003; Holtmann et al., 2010; Santiago, Tunik, Foltin, \& Mojica, 2006) with slightly higher percentage of youth with disruptive behavior disorders and slightly lower internalizing disorders, e.g. depression. This finding might reflect the higher urgency of externalizing which usually attracts more attention than do internalizing behaviors in our society. Several previous studies highlighted the role of admission in the management of psychiatric disorders that predicted the admission to our unit, especially bipolar disorders (Holtmann et al., 2010), trauma related disorders (Romansky, Lyons, Lehner, \& West, 2003), and eating disorders (Llanes-Alvarez et al., 2019). The small percentage of youth with eating disorders, most of which were sever enough to justify admission, might reflect the cultural shift towards western parameters of thinness (Makino, Tsuboi, \& Dennerstein, 2004). Having a diagnosis of autism spectrum disorder had a significant effect in decreasing the likelihood of admission into our unit, most probably due to lack of enough nursing staff needed to deal with sever aggressive and self-injurious behavior exhibited by some cases with sever autism. The less probability of admission of children with history of, delayed milestones, medical illness, or comorbid neurological disorders might be attributed to the referral of such cases into pediatric and neurological units for outpatient or inpatient care. The lower percentage of patients with family history of psychiatric disorders in our admitted sample might be explained by the denial of such history among the children of admitted children due to less education and more illiteracy.

Before concluding, it is important to highlight some of the limitations of the current study. First, the small size of our sample makes it difficult to generalize our results over the entire population. For example, only one case with sexual disorder and comorbid epilepsy stayed in our unit for a long duration led to the result that both sexual and neurological disorders were associated with longer duration of admission. Second, no data were collected from public or private psychiatric hospitals that do not have special units for children and adolescents but might admit youth on adult beds. Third, factors other than the actual condition of the patient, such as availability of human resources, sometimes affected the decision to admit a case. Fourth, socioeconomic status of the families was explored through informal questioning and not using a standardized tool to measure it. Finally, the source of referral of youth was not separately documented for each patient and hence no comparison between outpatient and inpatient groups was done.

\section{Conclusions}

Admitting children and adolescents in psychiatric inpatient units is a relatively new and still debatable practice in our Arab Egyptian society. We report that Egyptian youth with complex behavioral problems, such as in other parts of the world, desperately need and do get benefit from inpatient psychiatric service. Except for relatively higher rates of disruptive behavior disorders and less rates of eating disorders, the demographic and clinical characteristics of children in need for such service are not clearly different from those reported in other parts of the world. Further research is desperately needed to explore the actual needs of this population, the best practice to manage their problems, and the effectiveness of possible alternative services, such as day hospital or wrap-around services to replace admission. There is also a need to replicate our findings in other parts of the 
Arab world to identify the cultural aspects that might help or interfere with providing such service to children and adolescents in need.

\section{Abbreviations}

AACAP

the American Academy of Child and Adolescent psychiatry

ADHD

Attention Deficit-Hyperactivity Disorder

ASD

Autism Spectrum Disorder

BIF

Borderline Intellectual Functioning

DBD

Disruptive Behavior Disorders

DSM-5

Diagnostic and Statistical Manual of Mental Disorders - version 5

IBM

International Business Machines Corporation

ID

Intellectual Disability

IQ

Intelligence quotient

MINI-Kid

MINI International Neuropsychiatric Interview for Children and Adolescents for parents and with children and adolescents OCD

Obsessive Compulsive Disorder

OR

Odds Ratio

NY

New York

UK

United Kingdom

US

United States

USD

United Stated Dollar

\section{Declarations}

\section{Ethics approval and consent to participate:}

The study was approved by the Ethical Research Committee of the Faculty of Medicine, Tanta University under the code $33670 / 2 / 20$

\section{Consent for publication:}

All participating authors consent for publication

Availability of data and material: 
The dataset created and analyzed during the current study will be uploaded with the files and will be available from the corresponding author on request.

\section{Competing interests:}

All authors report no biomedical financial interests or potential conflicts of interest.

\section{Funding:}

This study was self-funded. No funds were received.

\section{Authors' information and contributions:}

Mohammad A. Seleem, MD.: Department of Psychiatry and Neurology, Faculty of Medicine, Tanta University, Tanta, Egypt.

Contribution: Confirming the diagnoses of all recruited subjects, Statistical analysis of the results, writing the manuscript, and responding to the reviewers' comments

Reham A. Amer, MD.: Department of Psychiatry and Neurology, Faculty of Medicine, Tanta University, Tanta, Egypt

Contribution: Supervising the process of interviewing families, reviewing the files of the subjects, shared in writing the manuscript.

\section{Acknowledgements:}

We would like to acknowledge the effort of our senior fellow Nehal Hatem M.Sc., our junior trainees; Dalia Elkafas, M.B.B.Ch., Lamis T. Shahin M.B.B.Ch., Lina E. Abd-Elaziz M.B.B.Ch., Mahmoud Atlam M.B.B.Ch., Noura M. Elkonaisy M.B.B.Ch., Yomna K. Marey M.B.B.Ch., who all helped in reviewing the files of this sample. We also show our deep gratitude to Ahmed El-Zawawy, clinical psychologist, who did the psychometric evaluation for youth in need, to Maha and Marwa Salah, our social workers who participated in evaluating the family status and background of children and adolescents before interviewing them. Finally, we appreciate the effort of our nursing staff in the Child and Adolescent Psychiatry unit at Tanta Psychiatry and Neurology Center. All thanks and gratitude to our families and parents.

\section{References}

1. (CAPMAS), E. C. A. f. P. M. A. S. (2016). Egypt in Numbers. Cairo.

2. (CAPMAS), E. C. A. f. P. M. A. S. (2018). Egypt in Numbers.

3. Association, A. P. (1957). Psychiatric Inpatient Treatment of Children. Baltimore: Lord Baltimore Press.

4. Association, A. P. (2013). DIAGNOSTIC AND STATISTICAL MANUAL OF MENTAL DISORDERS, FIFTH EDITION. In. Washington, DC: American Psychiatric Publishing.

5. Bardach, N. S., Coker, T. R., Zima, B. T., Murphy, J. M., Knapp, P., Richardson, L. P., . . Mangione-Smith, R. (2014). Common and costly hospitalizations for pediatric mental health disorders. Pediatrics, 133(4), 602-609. doi:10.1542/peds.2013-3165

6. Bharath, S., Srinath, S., Seshadri, S., \& Girimji, S. (1997). Child and adolescent psychiatry in-patient facility. Indian J Pediatr, 64(6), 829-832. doi:10.1007/bf02725505

7. Blader, J. C. (2004). Symptom, family, and service predictors of children's psychiatric rehospitalization within one year of discharge. J Am Acad Child Adolesc Psychiatry, 43(4), 440-451. doi:10.1097/00004583-200404000-00010

8. Blader, J. C. (2011). Acute inpatient care for psychiatric disorders in the United States, 1996 through 2007. Arch Gen Psychiatry, 68(12), 1276-1283. doi:10.1001/archgenpsychiatry.2011.84

9. Bobier, C., \& Warwick, M. (2005). Factors associated with readmission to adolescent psychiatric care. Aust N Z J Psychiatry, 39(7), 600-606. doi:10.1080/j.1440-1614.2005.01632.x

10. Boge, I., Schepker, R., \& Fegert, J. M. (2019). [Intensive psychiatric care of children and adolescents in their natural environment : Alternatives to inpatient treatment]. Bundesgesundheitsblatt Gesundheitsforschung Gesundheitsschutz, 62(2), 195-204. doi:10.1007/s00103-018-2874-0 
11. Boyer, L., Henry, J. M., Samuelian, J. C., Belzeaux, R., Auquier, P., Lancon, C., \& Da Fonseca, D. (2013). Mental Disorders among Children and Adolescents Admitted to a French Psychiatric Emergency Service. Emerg Med Int, 2013, 651530.

doi:10.1155/2013/651530

12. Branik, E. (2001). [Dangers and possible negative effects of inpatient child and adolescent psychiatric treatmentsrecognition and prevention]. Prax Kinderpsychol Kinderpsychiatr, 50(5), 372-382. Retrieved from https://www.ncbi.nlm.nih.gov/pubmed/11471424

13. Case, B. G., Olfson, M., Marcus, S. C., \& Siegel, C. (2007). Trends in the inpatient mental health treatment of children and adolescents in US community hospitals between 1990 and 2000. Arch Gen Psychiatry, 64(1), 89-96.

doi:10.1001/archpsyc.64.1.89

14. Corp., I. (Released 2011). IBM SPSS Statistics for Windows (Version 20.0). Armonk, NY.

15. Costello, E. J., Mustillo, S., Erkanli, A., Keeler, G., \& Angold, A. (2003). Prevalence and development of psychiatric disorders in childhood and adolescence. Arch Gen Psychiatry, 60(8), 837-844. doi:10.1001/archpsyc.60.8.837

16. Dwairy, M., \& Menshar, K. E. (2006). Parenting style, individuation, and mental health of Egyptian adolescents. J Adolesc, 29(1), 103-117. doi:10.1016/j.adolescence.2005.03.002

17. Edelsohn, G. A., Braitman, L. E., Rabinovich, H., Sheves, P., \& Melendez, A. (2003). Predictors of urgency in a pediatric psychiatric emergency service. J Am Acad Child Adolesc Psychiatry, 42(10), 1197-1202. doi:10.1097/00004583-20031000000010

18. Edgcomb, J. B., Sorter, M., Lorberg, B., \& Zima, B. T. (2020). Psychiatric Readmission of Children and Adolescents: A Systematic Review and Meta-Analysis. Psychiatr Serv, 71(3), 269-279. doi:10.1176/appi.ps.201900234

19. Edwards, D., Evans, N., Gillen, E., Longo, M., Pryjmachuk, S., Trainor, G., \& Hannigan, B. (2015). What do we know about the risks for young people moving into, through and out of inpatient mental health care? Findings from an evidence synthesis. Child Adolesc Psychiatry Ment Health, 9, 55. doi:10.1186/s13034-015-0087-y

20. El.Makzoum, H. (2015). Understanding Physical Punishment as a Method of Disciplining Children in Libya: The Perspectives of Parents, Children and Professionals. (PhD). The University of Sheffield,

21. Fuchs, M., Kemmler, G., Steiner, H., Marksteiner, J., Haring, C., Miller, C., . . Sevecke, K. (2016). Child and adolescent psychiatry patients coming of age: a retrospective longitudinal study of inpatient treatment in Tyrol. BMC Psychiatry, 16, 225. doi:10.1186/s12888-016-0910-x

22. Ghanem, S. (1998). Mini Kid schedule semi-structured interview. Institute of Psychiatry Ain Shams University.

23. Glick, I. D., Sharfstein, S. S., \& Schwartz, H. I. (2011). Inpatient psychiatric care in the 21 st century: the need for reform. Psychiatr Serv, 62(2), 206-209. doi:10.1176/ps.62.2.pss6202_0206

24. Green, J., Jacobs, B., Beecham, J., Dunn, G., Kroll, L., Tobias, C., \& Briskman, J. (2007). Inpatient treatment in child and adolescent psychiatry-a prospective study of health gain and costs. J Child Psychol Psychiatry, 48(12), 1259-1267. doi:10.1111/j.1469-7610.2007.01802.x

25. Grupp-Phelan, J., Mahajan, P., Foltin, G. L., Jacobs, E., Tunik, M., Sonnett, M., . . Pediatric Emergency Care Applied Research, N. (2009). Referral and resource use patterns for psychiatric-related visits to pediatric emergency departments. Pediatr Emerg Care, 25(4), 217-220. doi:10.1097/pec.0b013e31819e3523

26. Harper, G. G., R. . (1987). Hospital and residential treatment. In J. R. Michels \& J.O. Cavenar (Ed.), Psychiatry (Vol. 2). New York: Basic Books.

27. Healy, E., \& Fitzgerald, M. (2000). A 16-year follow-up of a child inpatient population. Eur Child Adolesc Psychiatry, 9(1), 4653. doi:10.1007/s007870050115

28. Holtmann, M., Duketis, E., Poustka, L., Zepf, F. D., Poustka, F., \& Bolte, S. (2010). Bipolar disorder in children and adolescents in Germany: national trends in the rates of inpatients, 2000-2007. Bipolar Disord, 12(2), 155-163. doi:10.1111/j.1399-

5618.2010.00794.x

29. Ibrahim M, B. Z., Hamed A. (2002). Comparison of Mini International Neuropsychiatric Interview for children (MINI-KID) with the schedules for affective disorders and schizophrenia for schoolaged children, present and lifetime version (KSADS-PL): In Egyptian sample presenting with childhood disorders. (MD). Ain Shams University, Cairo. 
30. Jacob, P., Seshadri, S., Girimaji, S. C., Srinath, S., \& Sagar, J. V. (2013). Clinical characteristics of aggression in children and adolescents admitted to a tertiary care centre. Asian J Psychiatr, 6(6), 556-559. doi:10.1016/j.ajp.2013.08.070

31. Jaffee, S. R., Harrington, H., Cohen, P., \& Moffitt, T. E. (2005). Cumulative prevalence of psychiatric disorder in youths. J Am Acad Child Adolesc Psychiatry, 44(5), 406-407. doi:10.1097/01.chi.0000155317.38265.61

32. James, A., Clacey, J., Seagroatt, V., \& Goldacre, M. (2010). Adolescent inpatient psychiatric admission rates and subsequent one-year mortality in England: 1998-2004. J Child Psychol Psychiatry, 51(12), 1395-1404. doi:10.1111/j.1469-

7610.2010.02293.x

33. James, S., Charlemagne, S. J., Gilman, A. B., Alemi, Q., Smith, R. L., Tharayil, P. R., \& Freeman, K. (2010). Post-discharge services and psychiatric rehospitalization among children and youth. Adm Policy Ment Health, 37(5), 433-445. doi:10.1007/s10488-009-0263-6

34. Jemerin, J. M., \& Philips, I. (1988). Changes in inpatient child psychiatry: consequences and recommendations. J Am Acad Child Adolesc Psychiatry, 27(4), 397-403. doi:10.1097/00004583-198807000-00001

35. Kennard, D. (1983). An Introduction to Therapeutic Communities. London, UK.: Routledge \& Kegan Paul.

36. Lewis, M. B. (1985). Residential treatment. In H. I. K. B. J. Sadock. (Ed.), Comprehensive Textbook of Psychiatry, IV, ed. (pp. 1798-1803). Baltimore: Williams \& Wilkins.

37. Llanes-Alvarez, C., Andres-de Llano, J. M., Alvarez-Navares, A. I., Pastor-Hidalgo, M. T., Roncero, C., \& Franco-Martin, M. A. (2019). Trends in Psychiatric Hospitalization of Children and Adolescents in Spain between 2005 and 2015. J Clin Med, 8(12). doi:10.3390/jcm8122111

38. Makino, M., Tsuboi, K., \& Dennerstein, L. (2004). Prevalence of eating disorders: a comparison of Western and non-Western countries. MedGenMed, 6(3), 49. Retrieved from https://www.ncbi.nlm.nih.gov/pubmed/15520673

39. Mattejat, F., Hirt, B. R., Wilken, J., Schmidt, M. H., \& Remschmidt, H. (2001). Efficacy of inpatient and home treatment in psychiatrically disturbed children and adolescents. Follow-up assessment of the results of a controlled treatment study. Eur Child Adolesc Psychiatry, 10 Supp/ 1, 171-79. doi:10.1007/s007870170008

40. Melika, L. (1998). The Stanford Binet Intelligence Scale. In Arabic Examiner's Handbook. (4th ed.). Cairo: Dar El Maref Publishing.

41. Mendonca, R., Pantano, T., Casella, C. B., \& Scivoletto, S. (2017). "Day Hospital in Child and Adolescent Psychiatry: Is It Effective for Whom?" Effectiveness of Infant Psychiatric Day Hospital. Journal of Psychiatry and Psychiatric Disorders, 01(06), 337-348. doi:10.26502/jppd.2572-519X0033

42. Moses, T. (2011). Stigma apprehension among adolescents discharged from brief psychiatric hospitalization. J Nerv Ment Dis, 199(10), 778-789. doi:10.1097/NMD.0b013e31822fc7be

43. O'Herlihy, A., Lelliott, P., Bannister, D., Cotgrove, A., Farr, H., \& Tulloch, S. (2018). Provision of child and adolescent mental health in-patient services in England between 1999 and 2006. Psychiatric Bulletin, 31(12), 454-456. doi:10.1192/pb.bp.106.013870

44. Egyptian Child Act, (2008 (amendment) - Original Act 1996).

45. Pfeiffer, S. I., \& Strzelecki, S. C. (1990). Inpatient psychiatric treatment of children and adolescents: a review of outcome studies. J Am Acad Child Adolesc Psychiatry, 29(6), 847-853. doi:10.1097/00004583-199011000-00001

46. Psychiatry, T. A. A. o. C. a. A. (1989). Inpatient Hospital Treatment of Children and Adolescents (Publication no. https://www.aacap.org/AACAP/Policy_Statements/1989/Inpatient_Hospital_Treatment_of_Children_and_Adolescents.aspx). Retrieved April 2020

47. Rachel N. Lipari, P. D., Sarra Hedden, Ph.D., Gary Blau, Ph.D., and Lisa Rubenstein, MHA. (2016). Adolescent mental health service use and reasons for using services in specialty, educational, and general medical settings (Publication no. https://www.samhsa.gov/data/sites/default/files/report_1973/ShortReport-1973.html). Retrieved April 21st, 2020, from Substance Abuse and Mental Health Services Administration (SAMHSA)

48. Romansky, J. B., Lyons, J. S., Lehner, R. K., \& West, C. M. (2003). Factors related to psychiatric hospital readmission among children and adolescents in state custody. Psychiatr Serv, 54(3), 356-362. doi:10.1176/appi.ps.54.3.356 
49. Santiago, L. I., Tunik, M. G., Foltin, G. L., \& Mojica, M. A. (2006). Children requiring psychiatric consultation in the pediatric emergency department: epidemiology, resource utilization, and complications. Pediatr Emerg Care, 22(2), 85-89.

doi:10.1097/01.pec.0000199568.94758.6e

50. Seleem, M. A., Amer, R. A., Romeh, A. H., \& Hamoda, H. M. (2019). Demographic and clinical characteristics of children seeking psychiatric services in the Nile Delta region: an observational retrospective study. Int J Ment Health Syst, 13, 66. doi:10.1186/s13033-019-0323-6

51. Sheehan D, L. Y., Sheehan K, Janavs J, Weiller E, Keskiner A, et al. (1997). The validity of the Mini International Neuropsychiatric Interview (MINI) according to the SCID-P and its reliability. . Eur Psychiatry, 12(5), 232-241.

52. Shepperd, S., Doll, H., Angus, R. M., Clarke, M. J., Iliffe, S., Kalra, L., . . Wilson, A. D. (2009). Avoiding hospital admission through provision of hospital care at home: a systematic review and meta-analysis of individual patient data. CMAJ, 180(2), 175-182. doi:10.1503/cmaj.081491

53. Simila, N., Hakko, H., Riipinen, P., \& Riala, K. (2018). Gender Specific Characteristics of Revolving Door Adolescents in Acute Psychiatric Inpatient Care. Child Psychiatry Hum Dev, 49(2), 225-233. doi:10.1007/s10578-017-0744-x

54. Swadi, H., \& Bobier, C. (2005). Hospital admission in adolescents with acute psychiatric disorder: how long should it be? Australas Psychiatry, 13(2), 165-168. doi:10.1080/j.1440-1665.2005.02181.x

55. Thorndike, R. L. H., E.P.; Sattler M. (1986). Stanford-Binet Intelligence Scale: Fourth Edition. Chicago: Riverside.

56. Vusio, F., Thompson, A., Birchwood, M., \& Clarke, L. (2019). Experiences and satisfaction of children, young people and their parents with alternative mental health models to inpatient settings: a systematic review. Eur Child Adolesc Psychiatry. doi:10.1007/s00787-019-01420-7

57. Weiss, C. L., Blizzard, A. M., Vaughan, C., Sydnor-Diggs, T., Edwards, S., \& Stephan, S. H. (2015). Supporting the transition from inpatient hospitalization to school. Child Adolesc Psychiatr Clin N Am, 24(2), 371-383. doi:10.1016/j.chc.2014.11.009

58. Worrall-Davies, A. J. a. A. (2015). Provision of intensive treatment: intensive outreach, day units, and in-patient units. In D. S. P. Anita Thapar, James F. Leckman, Stephen Scott, Margaret J. Snowling, Eric Taylor (Ed.), Rutter's Child and Adolescent Psychiatry (pp. 652, 654). Oxford, UK: JohnWiley \& Sons, Ltd.

\section{Tables}


Table (1):

Demographic characteristics of children admitted to the inpatient unit compared to those received only outpatient service $(n=1195)$

\begin{tabular}{|c|c|c|c|c|c|c|}
\hline \multicolumn{2}{|l|}{ Variable } & $\begin{array}{l}\text { Inpatient service }(n= \\
100)\end{array}$ & $\begin{array}{l}\text { Outpatient service only }(n= \\
1095)\end{array}$ & $\begin{array}{l}\text { Total }(n= \\
1195)\end{array}$ & Statistic & $\begin{array}{l}\mathrm{P} \\
\text { value }\end{array}$ \\
\hline \multicolumn{2}{|l|}{ Age } & $11.6 \pm 3.7$ & $7.4 \pm 3.8$ & $7.8 \pm 3.9$ & $t=10.5$ & $\leq .001$ \\
\hline \multirow[t]{3}{*}{ Age Category } & $\begin{array}{l}\text { Preschoolers } \\
\text { a }\end{array}$ & $5(5.0 \%)$ & $397(36.3 \%)$ & $402(33.6 \%)$ & \multirow[t]{3}{*}{$\begin{array}{l}x^{2}= \\
95.9\end{array}$} & \multirow[t]{3}{*}{$\leq .001$} \\
\hline & School Age ${ }^{b}$ & $41(41.0 \%)$ & $522(47.7 \%)$ & $563(47.1 \%)$ & & \\
\hline & $\begin{array}{l}\text { Adolescents } \\
\mathrm{c}\end{array}$ & $54(54.0 \%)$ & $176(16.1 \%)$ & $230(19.2 \%)$ & & \\
\hline \multicolumn{2}{|c|}{ Gender (Female) } & $25(25.0 \%)$ & 351 (32.1\%) & $376(31.5 \%)$ & $x^{2}=2.1$ & 0.1 \\
\hline \multirow[t]{2}{*}{ Residence } & Rural & $40(40.0 \%)$ & $650(59.4 \%)$ & $690(57.8 \%)$ & \multirow{2}{*}{$\begin{array}{l}x^{2}= \\
14.1\end{array}$} & \multirow{2}{*}{$\leq .001$} \\
\hline & Urban & $60(60.0 \%)$ & $444(40.6 \%)$ & 504 (42.2\%) & & \\
\hline \multicolumn{2}{|c|}{$\begin{array}{l}\text { Family Status } \\
\text { (Living with both parents) }\end{array}$} & $80(80.0 \%)$ & $975(89.0 \%)$ & $\begin{array}{l}1055 \\
(88.3 \%)\end{array}$ & $x^{2}=7.2$ & 0.007 \\
\hline \multirow[t]{3}{*}{$\begin{array}{l}\text { Father } \\
\text { Education }\end{array}$} & $\begin{array}{l}<\text { High } \\
\text { school a }^{\text {a }}\end{array}$ & 37 (37.0\%) & $276(25.3 \%)$ & $313(26.3 \%)$ & \multirow[t]{3}{*}{$x^{2}=6.5$} & \multirow[t]{3}{*}{0.04} \\
\hline & $\begin{array}{l}\text { High school } \\
b\end{array}$ & 35 (35.0\%) & $452(41.4 \%)$ & 487 (40.9\%) & & \\
\hline & $\begin{array}{l}\text { College } \\
\text { degree }^{b}\end{array}$ & $28(28.0 \%)$ & 364 (33.3\%) & 392 (32.9\%) & & \\
\hline \multirow[t]{3}{*}{$\begin{array}{l}\text { Mother } \\
\text { Education }\end{array}$} & $\begin{array}{l}<\text { High } \\
\text { school }\end{array}$ & 33 (33.0\%) & 295 (27.0\%) & $328(27.5 \%)$ & \multirow[t]{3}{*}{$x^{2}=2.6$} & \multirow[t]{3}{*}{0.3} \\
\hline & High school & $43(43.0 \%)$ & $460(42.1 \%)$ & $503(42.2 \%)$ & & \\
\hline & $\begin{array}{l}\text { College } \\
\text { degree }\end{array}$ & $24(24.0 \%)$ & 337 (30.9\%) & 361 (30.3\%) & & \\
\hline \multirow[t]{2}{*}{$\begin{array}{l}\text { Family } \\
\text { Income }\end{array}$} & $\begin{array}{l}<5000 \\
\text { EGP/M }\end{array}$ & $66(66.0 \%)$ & $720(65.8 \%)$ & 840 (65.9\%) & \multirow[t]{2}{*}{$\begin{array}{l}x^{2}= \\
0.002\end{array}$} & \multirow[t]{2}{*}{0.9} \\
\hline & $\begin{array}{l}\geq 5000 \\
\mathrm{EGP} / \mathrm{M}\end{array}$ & $34(34.0 \%)$ & $375(34.2 \%)$ & 409 (34.2\%) & & \\
\hline \multirow[t]{3}{*}{$\begin{array}{l}\text { Child } \\
\text { Education }\end{array}$} & $\begin{array}{l}\text { Out of } \\
\text { school }\end{array}$ & $7(7.4 \%)$ & $48(6.9 \%)$ & $55(6.9 \%)$ & \multirow[t]{3}{*}{ FET } & \multirow[t]{3}{*}{0.6} \\
\hline & $\begin{array}{l}\text { Regular } \\
\text { school }\end{array}$ & 87 (91.6\%) & $628(90.0 \%)$ & 715 (90.2\%) & & \\
\hline & $\begin{array}{l}\text { Special } \\
\text { school }\end{array}$ & $1(1.1 \%)$ & $22(3.2 \%)$ & $23(2.9 \%)$ & & \\
\hline
\end{tabular}


Table (2):

Clinical characteristics of children admitted to the inpatient unit compared to those received only outpatient service $(n=1195)$

\begin{tabular}{|c|c|c|c|c|c|c|}
\hline \multicolumn{2}{|l|}{ Variable } & $\begin{array}{l}\text { Inpatient service ( } \mathrm{n} \\
=100)\end{array}$ & $\begin{array}{l}\text { Outpatient service only ( } \mathrm{n} \\
=1095 \text { ) }\end{array}$ & $\begin{array}{l}\text { Total }(n= \\
1195)\end{array}$ & Statistic & $\begin{array}{l}\mathrm{p} \\
\text { value }\end{array}$ \\
\hline \multicolumn{2}{|l|}{ IQ } & $79.8 \pm 11.4$ & $78.2 \pm 12.2$ & $\begin{array}{l}78.4 \pm \\
12.1\end{array}$ & $\mathrm{t}=0.8$ & 0.3 \\
\hline \multicolumn{2}{|c|}{ Family History of Psychiatric Illness } & $10(10.0 \%)$ & $194(17.8 \%)$ & $\begin{array}{l}204 \\
(17.1 \%)\end{array}$ & $x^{2}=3.9$ & 0.05 \\
\hline \multicolumn{2}{|c|}{ History of Birth Complications } & $3(3.0 \%)$ & $228(20.9 \%)$ & $\begin{array}{l}231 \\
(19.4 \%)\end{array}$ & $\begin{array}{l}x^{2}= \\
18.8\end{array}$ & $\leq .001$ \\
\hline \multicolumn{2}{|c|}{ History of Delayed Milestones } & $26(26.0 \%)$ & $520(47.7 \%)$ & $\begin{array}{l}546 \\
(45.9 \%)\end{array}$ & $\begin{array}{l}x^{2}= \\
17.4\end{array}$ & $\leq .001$ \\
\hline \multicolumn{2}{|c|}{ History of Medical IIIness } & $6(6.0 \%)$ & $271(24.8 \%)$ & $\begin{array}{l}277 \\
(23.2 \%)\end{array}$ & $\begin{array}{l}x^{2}= \\
18.1\end{array}$ & $\leq .001$ \\
\hline \multicolumn{2}{|c|}{ Birth Order (5th or more) } & $3(2.7 \%)$ & $19(1.6 \%)$ & $22(1.7 \%)$ & FET & 0.4 \\
\hline \multirow{4}{*}{$\begin{array}{l}\text { History of } \\
\text { Abuse }\end{array}$} & None $\mathrm{a}^{\mathrm{a} b}$ & $62(62.0 \%)$ & $728(66.9 \%)$ & $790(66.5)$ & \multirow[t]{4}{*}{ FET } & \multirow{4}{*}{$\leq .001$} \\
\hline & $\begin{array}{l}\text { Physical } \\
\text { Punishment }{ }^{a}\end{array}$ & $17(17.0 \%)$ & $257(23.6 \%)$ & $\begin{array}{l}274 \\
(23.1 \%)\end{array}$ & & \\
\hline & Physical Abuse ${ }^{b}$ & $13(13.0 \%)$ & $88(8.1 \%)$ & $101(8.5 \%)$ & & \\
\hline & Sexual Abuse ${ }^{c}$ & $9(8.0 \%)$ & $15(1.4 \%)$ & $23(1.9 \%)$ & & \\
\hline \multicolumn{2}{|c|}{ Comorbid diagnosis } & $41(41.0 \%)$ & $428(39.1 \%)$ & $\begin{array}{l}469 \\
(39.2 \%)\end{array}$ & $x^{2}=0.1$ & 0.7 \\
\hline
\end{tabular}

FET: Fisher Exact Test

Different superscripts denote significant between-group differences calculated using pair-wise chi-square tests ( $p$-values $\leq$ 0.05) 
Table (3):

Diagnostic categories of children admitted to the inpatient unit compared to those received only outpatient service $(n=1195)$

\begin{tabular}{|c|c|c|c|c|c|}
\hline Diagnostic category & $\begin{array}{l}\text { Inpatient service }(n= \\
100)\end{array}$ & $\begin{array}{l}\text { Outpatient service only }(n= \\
1095)\end{array}$ & $\begin{array}{l}\text { Total }(n= \\
1195)\end{array}$ & Statistic & $\begin{array}{l}\mathrm{p} \\
\text { value }\end{array}$ \\
\hline Depressive Disorders & $18(18.0 \%)$ & $155(14.2 \%)$ & $173(14.5 \%)$ & $x^{2}=1.1$ & 0.3 \\
\hline Bipolar Disorders & $5(5.0 \%)$ & $4(0.4 \%)$ & $9(0.8 \%)$ & FET & $\begin{array}{l}\leq \\
0.001\end{array}$ \\
\hline Anxiety Disorders & $2(2.0 \%)$ & $38(3.5 \%)$ & $40(3.3 \%)$ & FET & 0.8 \\
\hline Psychotic Disorders & $5(5.0 \%)$ & $15(1.4 \%)$ & $20(1.7 \%)$ & FET & 0.02 \\
\hline ADHD & $22(22.0 \%)$ & $298(27.2 \%)$ & $320(26.8 \%)$ & $x^{2}=1.3$ & 0.3 \\
\hline DBD & $42(42.0 \%)$ & $126(11.5 \%)$ & $168(14.1 \%)$ & $\begin{array}{l}x^{2}= \\
70.5\end{array}$ & $\begin{array}{l}\leq \\
0.001\end{array}$ \\
\hline ASD & $2(2.0 \%)$ & 115 (10.5\%) & 117 (9.8\%) & $x^{2}=7.5$ & 0.006 \\
\hline $\begin{array}{l}\text { Communication } \\
\text { Disorders }\end{array}$ & $1(1.0 \%)$ & 119 (10.9\%) & $120(10.0 \%)$ & $x^{2}=9.9$ & 0.002 \\
\hline OCD spectrum & $4(4.0 \%)$ & $15(1.4 \%)$ & $19(1.6 \%)$ & FET & 0.07 \\
\hline $\begin{array}{l}\text { Somatic Related } \\
\text { Disorders }\end{array}$ & $1(1.0 \%)$ & $12(1.1 \%)$ & $13(1.1 \%)$ & FET & 1.0 \\
\hline $\begin{array}{l}\text { Trauma Related } \\
\text { Disorders }\end{array}$ & $3(3.0 \%)$ & $5(0.5 \%)$ & $8(0.7 \%)$ & FET & 0.02 \\
\hline Tics & $2(2.0 \%)$ & $25(2.3 \%)$ & $27(2.3 \%)$ & FET & 1.0 \\
\hline Elimination Disorders & $5(5.0 \%)$ & $137(12.5 \%)$ & $142(11.9 \%)$ & $x^{2}=4.9$ & 0.03 \\
\hline Eating Disorders & $2(2.0 \%)$ & $2(0.2 \%)$ & $4(0.3 \%)$ & FET & 0.04 \\
\hline Sexual Disorders & $1(1.0 \%)$ & $3(0.3 \%)$ & $4(0.3 \%)$ & FET & 0.3 \\
\hline BIF & $30(30.0 \%)$ & $284(25.9 \%)$ & $314(26.3 \%)$ & $x^{2}=0.8$ & 0.4 \\
\hline Intellectual Disability & $9(9.0 \%)$ & $152(13.9 \%)$ & 161 (13.5\%) & $x^{2}=1.9$ & 0.2 \\
\hline Neurological Disorders & $1(1.0 \%)$ & 107 (9.8\%) & $108(9.0 \%)$ & $x^{2}=8.6$ & 0.001 \\
\hline
\end{tabular}


Table (4):

Univariate logistic and linear regression analyses for the demographic and clinical variables predicting admission, number of admissions, and duration of last admission

\begin{tabular}{|c|c|c|c|}
\hline \multirow[t]{2}{*}{ Variables } & $\begin{array}{l}\text { Admission }(n= \\
1195)\end{array}$ & $\begin{array}{l}\text { No. of admissions }(n= \\
100)\end{array}$ & $\begin{array}{l}\text { Duration of last admission }(n= \\
100)\end{array}$ \\
\hline & OR (95\% C.I) & B (95\% C.I) & B (95\% C.I) \\
\hline Age & $1.3(1.2-1.4) * \star$ & & $0.7(1.1-1.3)$ * \\
\hline Age Category & & & $4.7(1.1-8.2)$ * \\
\hline Preschoolers $(1-5) \AA$ & - & & \\
\hline School age $(6-11)$ & $6.2(2.4-15.9)$ ** & & \\
\hline Adolescents (12-18) & $24.4(9.6-61.9) * \star$ & & \\
\hline Urban Residence & $2.2(1.4-3.3) * *$ & & \\
\hline \multicolumn{4}{|l|}{ Marital status } \\
\hline Living with both parents ${ }^{\circledR}$ & - & & \\
\hline One parent deceased & $3.6(1.6-8.2)$ * & & \\
\hline \multicolumn{4}{|l|}{ Father Education } \\
\hline High Education® & - & & \\
\hline Illiterate & $1.9(1.1-3.8)$ * & & \\
\hline Being out of school & & & $7.4(0.6-14.2)$ * \\
\hline $\begin{array}{l}\text { History of medical illness } \\
\text { (Child) }\end{array}$ & $0.2(0.1-0.5) * *$ & & \\
\hline Birth Complication & $0.2(0.04-0.4) * \star$ & & \\
\hline Delayed Milestones & $0.4(0.2-0.6) * \star$ & & \\
\hline Child Abuse (None®) & & $0.2(0.07-0.3)$ * & $2.3(0.2-4.5)$ * \\
\hline \multicolumn{4}{|l|}{ Harsh Physical punishment } \\
\hline \multicolumn{4}{|l|}{ Physical abuse } \\
\hline Sexual abuse & $6.3(2.6-15.3) * \star$ & & \\
\hline Bipolar disorders & $14.4(3.8-54.4) * \star$ & & \\
\hline Psychotic disorders & $3.8(1.3-10.7)$ * & $0.7(0.1-1.3)$ * & \\
\hline Disruptive disorders & $5.6(3.6-8.6)$ *ᄎ & $0.3(0.001-0.5)$ * & \\
\hline Autism spectrum disorder & $0.2(0.04-0.7)$ * & & \\
\hline Communication disorders & $0.08(0.01-0.6)$ * & & \\
\hline Trauma related disorders & $6.7(1.6-28.6)$ * & & \\
\hline Elimination disorders & $0.4(0.2-0.9)$ * & & \\
\hline Eating disorders & $11.2(1.6-80.0)$ * & & \\
\hline
\end{tabular}

OR: Odd`s ratio; C.I: Confidence interval; ${ }^{\circledR}$ reference;

*: Statistically significant at $p \leq 0.05$; **: Statistically significant at $p \leq 0.001$ 


\begin{tabular}{|c|c|c|c|}
\hline \multirow[t]{2}{*}{ Variables } & $\begin{array}{l}\text { Admission }(n= \\
1195)\end{array}$ & $\begin{array}{l}\text { No. of admissions }(n= \\
100)\end{array}$ & $\begin{array}{l}\text { Duration of last admission }(n= \\
100)\end{array}$ \\
\hline & OR (95\% C.I) & B (95\% C.I) & B (95\% C.I) \\
\hline \multicolumn{3}{|l|}{ Sexual disorders } & $26.7(5.5-47.9)$ * \\
\hline Neurologic disorders & \multicolumn{2}{|l|}{$0.1(0.01-0.7)$ * } & $26.7(5.5-47.9)$ * \\
\hline \multicolumn{4}{|c|}{ OR: Odd`s ratio; C.I: Confidence interval; ® reference; } \\
\hline \multicolumn{4}{|c|}{ *: Statistically significant at $p \leq 0.05 ; * \star$ : Statistically significant at $p \leq 0.001$} \\
\hline
\end{tabular}

\section{Figures}

\section{School age}

Adolescents

Urban residence

Parent deceased

Father illiterate

History of medical illness

Birth complications

Delayed milestones

\section{Sexual abuse}

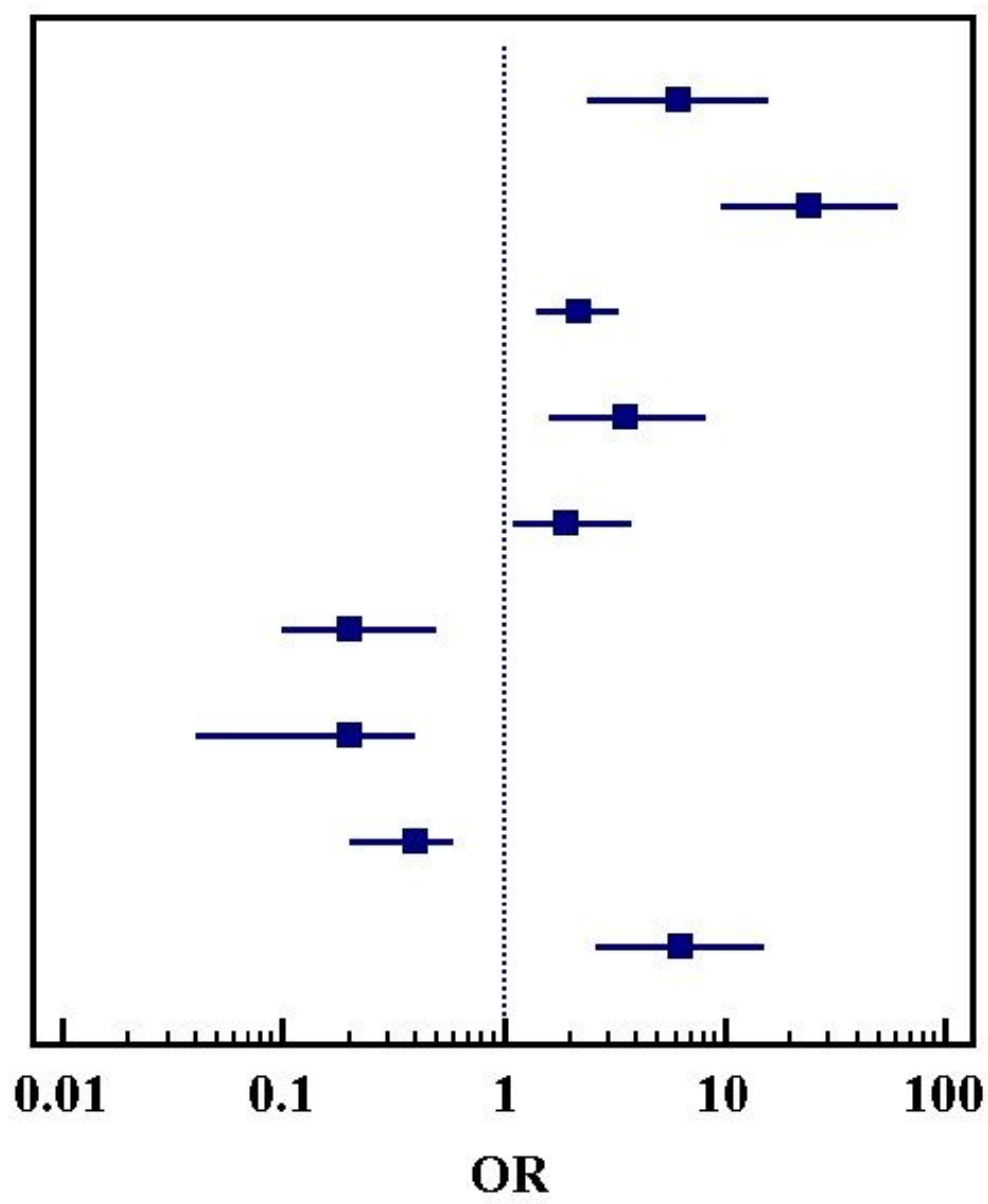

Figure 1

Demographic and clinical variables significantly predicting the admission into inpatient unit 
Bipolar disorders

Psychotic disorders

Disruptive disorders

Autism spectrum disorder

Communication disorders

Trauma related disorders

Elimination disorders

Eating disorders

Neurologic disorders

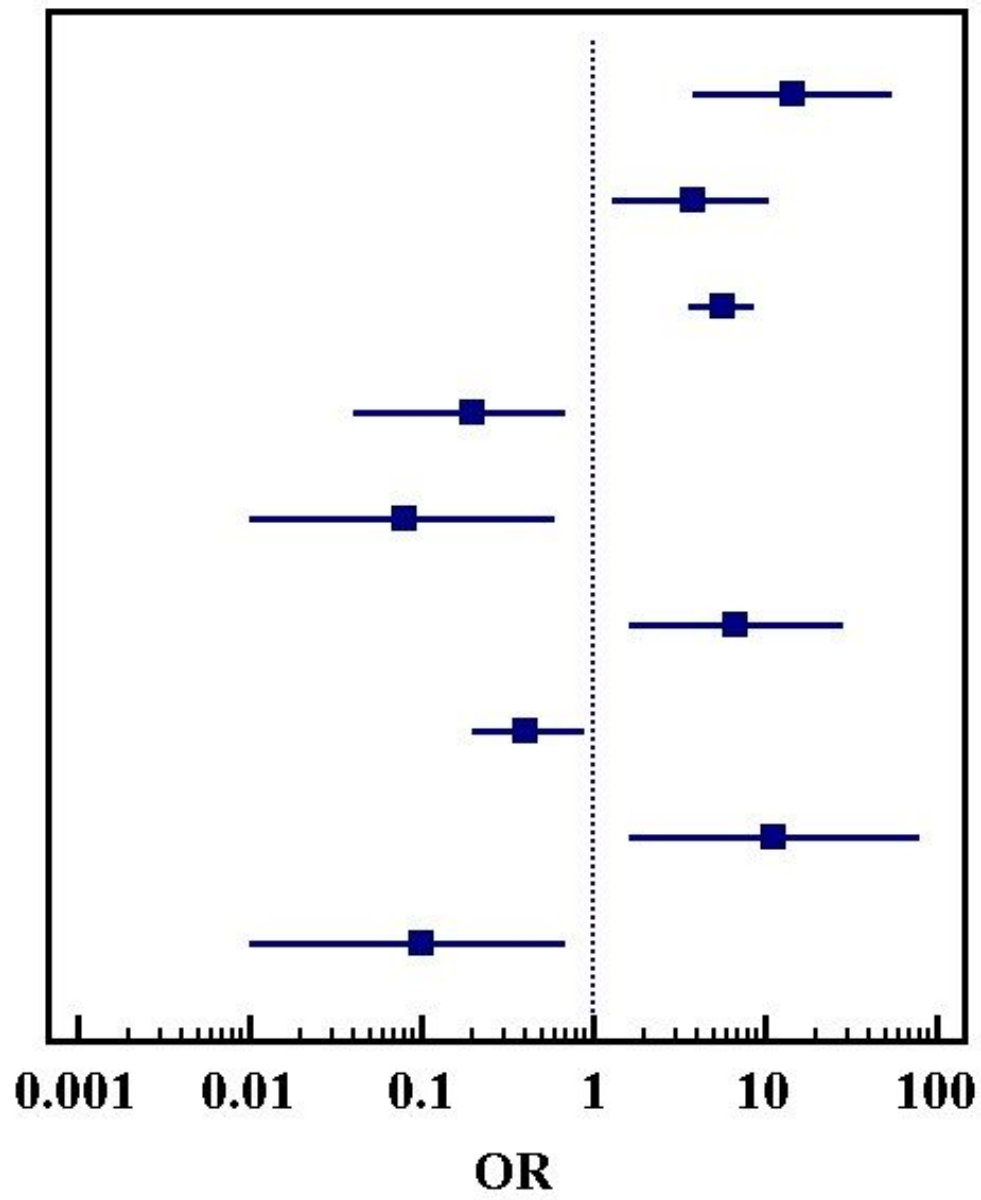

Figure 2

Diagnostic categories significantly predicting the admission into inpatient unit 


\section{Child Abuse}

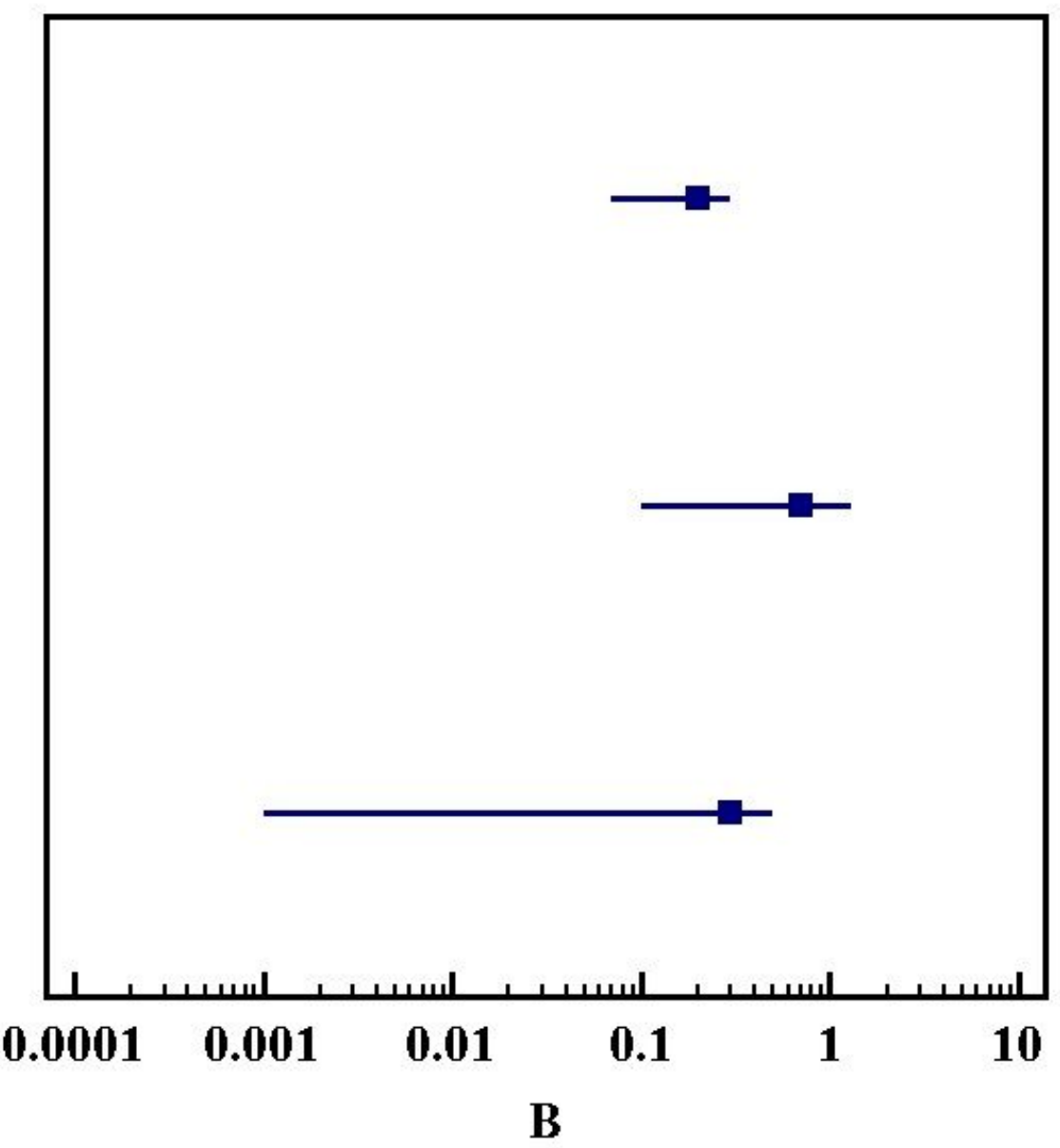

Disruptive disorders

Psychotic disorders

\section{Figure 3}

Factors significantly predicting the number of admission episodes in inpatient unit 


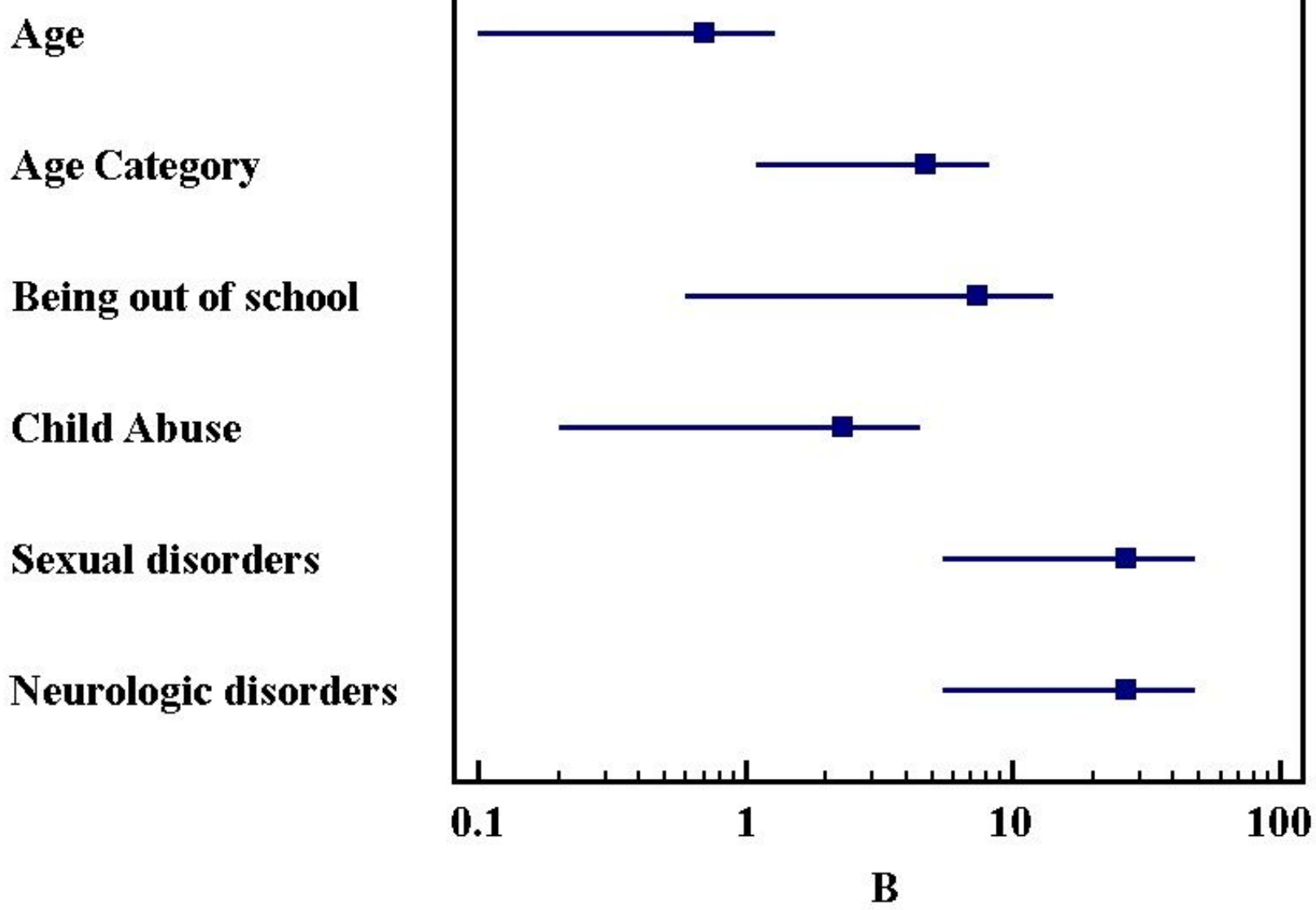

Figure 4

Factors significantly predicting the duration of admission in inpatient unit 